\title{
静滴法による溶融純金属 $(\mathrm{Cu}, \mathrm{Ag}, \mathrm{Sn})$ による $\mathrm{SiC}$ 繊維の \\ 濡れ性の測定*
}

\author{
野城 清** 上坂伸哉*** 荻野和 巳**
}

J. Japan Inst. Metals, Vol. 53, No. 8 (1989), pp. 828-833

Wettability Measurement of SiC Fibre by Liquid Pure Metals (Cu, Ag, Sn) with Sessile Drop Method

Kiyoshi Nogi**, Shin-ya Uesaka*** and Kazumi Ogino ${ }^{* *}$

The validity of the sessile drop method was examined to determine the wettability of the $\mathrm{SiC}$ fibre which has a finite curvature and contact angles of liquid pure $\mathrm{Cu}, \mathrm{Sn}$ and $\mathrm{Ag}$ were measured on 2 types of $\mathrm{SiC}$ fibres.

Main results are as follows:

(1) The sessile drop method is applicable to measure the contact angle of liquid metal on $\mathrm{SiC}$ fibre which has a finite curvature.

(2) Liquid pure metal ( $\mathrm{Cu}, \mathrm{Sn}$ and $\mathrm{Ag}) / \mathrm{SiC}$ fibre systems are non-wetting ones.

(3) The results obtained are comparable with the previous work for $\mathrm{SiC}$ substrate.

(Received April 27, 1989)

Keywords: wettability, contact angle, liquid metal, SiC, composites, joining

\section{I . 緒言}

金属基複合材料（MMC）の製造に括いて，溶融金属に上 るセラミックスの濡れ性は材料の強度などの特性を大きく 左右する因子であるとされている。

金属基複合材料の中で焉繊維強化金属(FRM) は高温に 和ける材料特性が優れているために多くの分野において今 後ますますその需要が放大するすのと思われる。

このよらな背景のもとでFRMに関する研究は現在, 数 多く行われているが, 金属マトリックスと強化䋐維との界 面特性，とくにFRM の製造時に重要な情報を与学る濡れ 性などの基礎的な研究はほとんど行われていないのが現状 である。

著者らは現在までに種々の溶融金属による $\mathrm{SiC} の$ 濡れ 性に関しての報告を行い(1)-(4), 同一の金属によっても， $\mathrm{SiC}$ の濡孔性は $\mathrm{SiC}$ 表面性状によっていらじるしく異 なることを明らかにした。したがって，聿用に供される $\mathrm{SiC}$ 繊維の濡れ性の測定およびその評価方法を確立する必 要があるが，緘維は通常その直径が数十川mであるため， 嗞来の霞れ性の測定方法をそのまま適用することは困難で あると考えられ，その報告例本はとえど見当らない。
本研究に就いては，溶融金属による $\mathrm{SiC}$ 織維の濡九性 の測定に促来の静滴法の適用の妥当性を検討するととも に, 種々の溶融純金属 $(\mathrm{Cu}, \mathrm{Sn}, \mathrm{Ag})$ による2種類の $\mathrm{SiC}$ 繊 維の濡れ性の測定を行い，著者らが以前に報告した $\mathrm{SiC}$ 基盤の濡れ性の測定結果(1)-(4)との比較検討を行った。

\section{II. 実験}

1. 試 料

\section{(1) $\mathrm{SiC}$ 緎維}

実験には市販の 2 種類の $\mathrm{SiC}$ 長繊維 $(\mathrm{A}, \mathrm{B})$ を用いた。 いずれも，CVDにより製造されたるのである。緎維の直

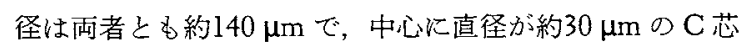

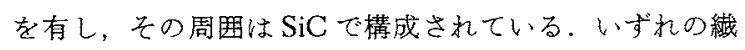
維もFig. 1 に示す Auger 分析から明らかなよらに，Cに

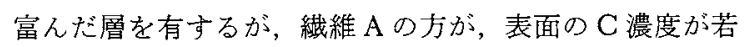
干高く，またCに富んた層の厚みが薄い。

(2) 金属試料

以下に本研究で使用した金属粉末試料の概要を示す.

(1) $\mathrm{Cu}$ 試料：純度 $99.85 \%, 250$ meshの粉末試料を, 酸素の除去のため浄化した水素気流中, $600 \mathrm{~K}$ で約 $11 \mathrm{ks}$ 保持し，脱酸した日居湘定に供した，脱酸後の酸素含有

* 1989年 4 月日本金属学会横浜大会に発表

**大阪大学工学部材料開発工学科(Department Materials Science and Processing, Faculty of Engineering, Osaka University, Suita)

** 大阪大学学生, 現在 : 大阪大学大学院生 (Undergraduate Student, Osaka University, Suita. Present address: Graduate Student, Osaka University, Suita) 


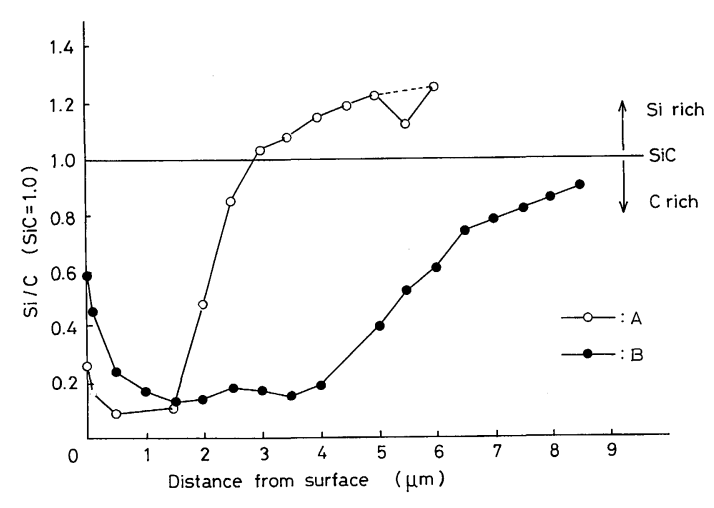

Fig. 1 Auger analysis of the surface of SiC fibres.

量は400 ppm であった。

(2) Ag 試料：純度 $99 \%$ 以上, 200 mesh の粉末試料を 用いた。酸素含有量は320 ppm であった。

（3） Sn 試料：純度 $95 \%$ 以上，200 meshの粉末試料を 用いた。酸素含有量は580 ppm であった。

\section{2. 実験装置および方法}

濡れの測定に用いた炉の概略を Fig. 2 に示す．炉は高 温顕微鏡を改良し, 滴の形状観察のための観察空を有した ものであり，Mo 線を発熱体としている．测定は $\mathrm{Ar}+$ $5 \% \mathrm{H}_{2}$ 雾囲気あるいは $10^{-4} \mathrm{~Pa}$ の減圧下で行った.

本研究においては滴は直径 $100 \mu \mathrm{m}$ 程度と非常に小さい ものであるため, 滴の形状の撮影には顕微鏡写真撮影装置 を備えた実体顕微鏡を用い，120倍の撮影倍率で撮影し た。

測定はまずアセトンで $\mathrm{SiC}$ 繊維を洗浄後，低温に打い て金属粉末を $\mathrm{SiC}$ 繊維上に保持するためにエチレングリ ーコールを塗布した後, 金属粉末をのせる. $\mathrm{SiC}$ 繊維を炉 内に水平にセットした後排気し， $10^{-4} \mathrm{~Pa}$ 以下の真空度に 到達したことを確認した後, 昇温を開始する $\left(\mathrm{Ar}+\mathrm{H}_{2}\right.$ 䨌 囲気での測定の場合には $10^{-4} \mathrm{~Pa}$ 以下の真空度に到達した ことを確認した後, 䨌囲気ガスを炉内に充填し, 約7.2 ks の間ガスを流した後，昇温を開始した.).

炉の昇温はいずれの雾囲気においても $60 \mathrm{~s}$ あたり $20 \mathrm{~K}$ の昇温速度で行った. ただし，エチレングリーュールの沸

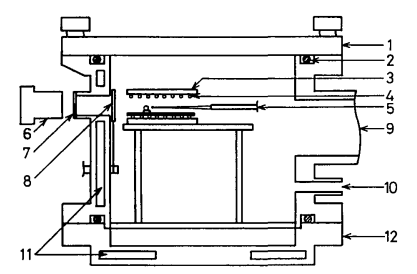

$$
\begin{aligned}
& \text { 1. Top cover } \\
& \text { 2. O-ring } \\
& \text { 3. Ceramic mold } \\
& \text { 4. Molybdenum heate coil } \\
& \text { 5. Thermocouple } \\
& \text { 6. Obsevating window } \\
& \text { 7. Photomicrographic system } \\
& \text { 8. Shutter } \\
& \text { 9. Vacuum pipe connected to } \\
& \text { diffusion pump or gas } \\
& \text { inlet (as case may be) } \\
& \text { 10. Gas outlet } \\
& \text { 11. Water cooling jacket } \\
& \text { 12. Base cover }
\end{aligned}
$$

Fig. 2 Apparatus for measurement.
点 $(470 \mathrm{~K})$ と金属試料の融点付近では, 昇温速度を若干遅 くした. 金属試料の溶解を確認した後, 昇温過程での溶融 金属と $\mathrm{SiC}$ 繊維との反応を避けるため, 測定温度まで急 速に昇温した．測定温度に到達した時点を測定開始時間と し, 以後滴の形状を適宜写真撮影した.

測定終了後は, 炉内の温度が $800 \mathrm{~K}$ に到達するまで $60 \mathrm{~s}$ あたり $35 \mathrm{~K}$ の速度で冷却し, 以後電源を切り, 速やかに 試料を冷却した。

凝固後の試料は埋め込み樹脂に埋め込んだ後, 繊維軸方 向に対して垂直に切断し, 研摩した後 EPMAによって, 界面の観察を行った.

\section{III. 結 果}

本研究においては金属液滴の大きさはその最大径の直径 が大きい場合で約 $100 \mu \mathrm{m}$ 程度と非常に小さく, 重力の影 響が無視できると考えられ，このような場合には固体表面 上の液滴は球の一部とみなすことができるとされている(5). そのような場合には，Fig. 3 に示すように $x, y$ を測定する

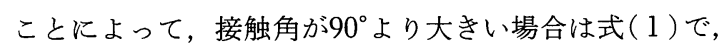
$90^{\circ}$ よりさい場合は式 ( 2 )であらわすことができる.

$$
\begin{aligned}
& \theta=90+\tan ^{-1}(y / x) \text { (degree) } \\
& \theta=2 \tan ^{-1}(y / x) \text { (degree) }
\end{aligned}
$$

Fig. 4 に結果の一例として $\mathrm{SiC}$ 繊維上の溶融金属滴の 形状を写真撮影した結果を示す. 滴の対称性はかなり良 く, 本研究で得られた接触角の測定誤差は同一条件での複 数回の測定から士 $3^{\circ}$ と見積った.

\section{1. 溶融純 $\mathrm{Cu}$ と $\mathrm{SiC}$ 繊維との接触角}

種々の条件下で得られた溶融純 $\mathrm{Cu}$ と $\mathrm{SiC}$ 繊維との接

(1) $\theta>90^{\circ}$

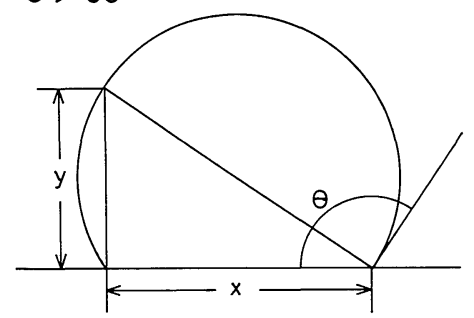

(2) $\theta<90^{\circ}$

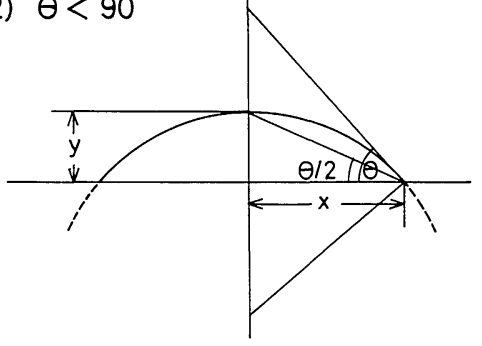

Fig. 3 Measured parameters of drops for calculation of contact angles by eqs. (1) and (2). 
触角の值を著者らが以前に報告した $\mathrm{SiC}$ 基盤上の結果 ${ }^{(1)}$ とともにFig. 5 扎よびFig. 6 に示す.

溶融純 $\mathrm{Cu}$ と $\mathrm{SiC}$ 繊維との接触角はいずれの条件にお
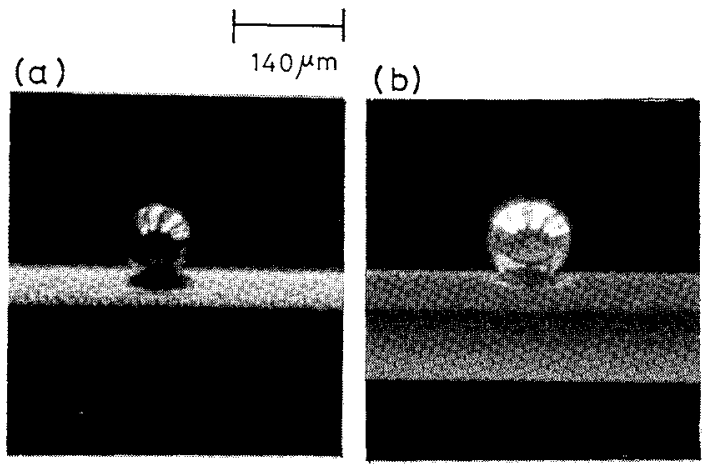

Fig. 4 Typical shapes of liquid metal drops on $\mathrm{SiC}$ fibre. (a) liquid $\mathrm{Cu}$ at $1393 \mathrm{~K}$, (b) liquid $\mathrm{Cu}$ at $1443 \mathrm{~K}$.

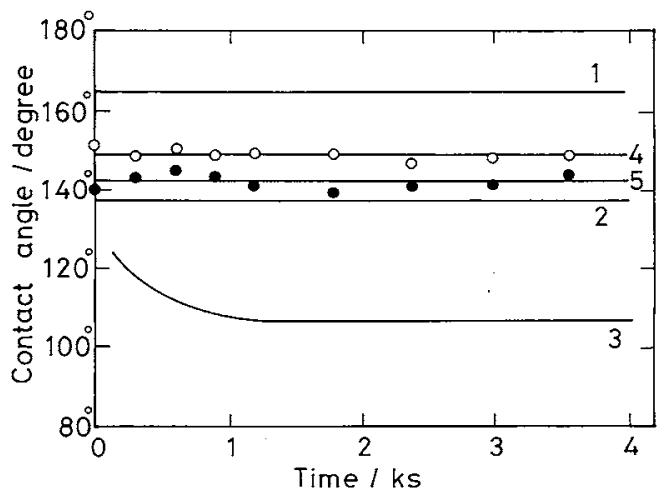

Fig. 5 Time dependence of the contact angle of liquid pure $\mathrm{Cu}$ on $\mathrm{SiC}$.

1: Hot-pressed $\mathrm{SiC}$ at $1408 \mathrm{~K}^{(1)}$.

2: Hot-pressed $\mathrm{SiC}+1$ mass $\% \mathrm{~B}_{4} \mathrm{C}$ at $1408 \mathrm{~K}^{(1)}$.

3: Reaction-bonded $\mathrm{SiC}$ at $1408 \mathrm{~K}^{(1)}$.

4: Present work, SiC fibre (A) at $1393 \mathrm{~K}$.

5: Present work, SiC fibre (A) at $1443 \mathrm{~K}$.

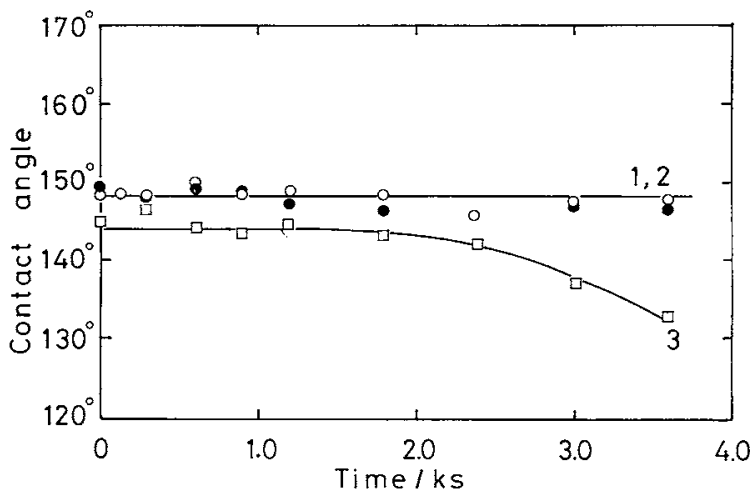

Fig. 6 Time dependence of the contact angle of liquid pure $\mathrm{Cu}$ on $\mathrm{SiC}$ under reduced pressure.

1: $\mathrm{SiC}$ fibre (A) at $1393 \mathrm{~K}$.

2: $\mathrm{SiC}$ fibre (B) at $1393 \mathrm{~K}$.

3: $\mathrm{SiC}$ fibre (A) at $1443 \mathrm{~K}$.
いても $90^{\circ}$ 以上の值を示し，繊維の相違による接触角の相 違は測定誤差内であった。

Fig. 5 の $\mathrm{Ar}+5 \% \mathrm{H}_{2}$ 雾囲気では接触角の時間変化は $1393 \mathrm{~K}, 1443 \mathrm{~K}$ のいずれの温度に和いても観察されなかっ たが，Fig. 6 の1443Kに拈ける減圧下での測定では時間 の経過にともない接触角の隇少がみみられた。

\section{2. 溶融純 $\mathrm{Ag} と \mathrm{SiC}$ 繊維との接触角}

Fig. 7 に溶融 $\mathrm{Ag}$ と $\mathrm{SiC}$ 繊維との接触角の著者らが以前 に報告した $\mathrm{SiC}$ 基盤上の結果(3) とともに示す.

$1323 \mathrm{~K}$ の測定においては接触角の時間変化はみられな かったが， $1373 \mathrm{~K}$ の測定では接触角は時間の経過にとも なって娍少し，いずれの蟣維の場合においても液滴表面の 金属光沢が徐々に失われ，固相の析出によると思われる凹 凸が表面に生じた。

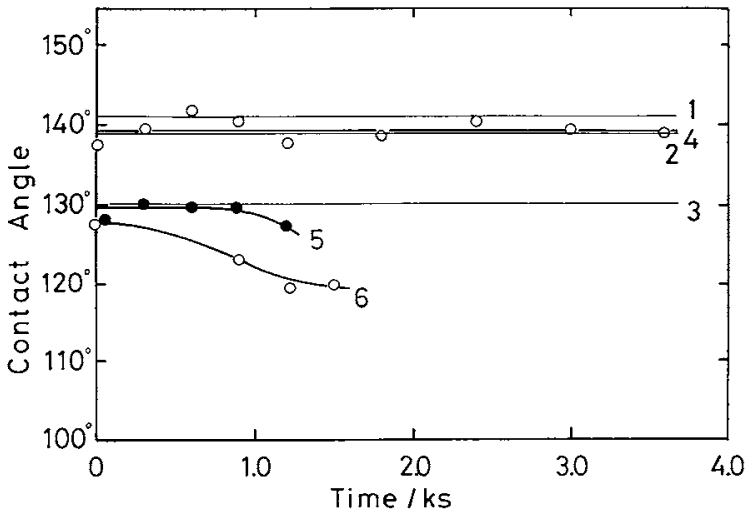

Fig. 7 Time dependence of the contact angle of liquid pure $\mathrm{Ag}$ on $\mathrm{SiC}$.

1: Hot-pressed $\mathrm{SiC}$ at $1283 \mathrm{~K}^{(1)(3)}$.

2: Carbon treated reaction-bonded $\mathrm{SiC}$ at $1283 \mathrm{~K}^{(3)}$.

3: Reaction-bonded $\mathrm{SiC}$ at $1283 \mathrm{~K}^{(1)(3)}$.

4: Present work, SiC fibre (A) at $1323 \mathrm{~K}$.

5: Present work, SiC fibre (A) at $1373 \mathrm{~K}$.

6: Present work, SiC fibre (B) at $1373 \mathrm{~K}$.

\section{3. 溶融純 $\mathrm{Sn} と \mathrm{SiC}$ 瀻維との接触角}

Fig. 8 に溶融 $\mathrm{Sn}$ と $\mathrm{SiC}$ 穖維との接触角の著者らが以前 に報告した $\mathrm{SiC}$ 基盤上の結果(1)とともに示す.

本実験条件下に拉いては，いずれの繊維の場合において 6 $145^{\circ}$ 以上の高い值を示し，接触角の時間変化はみられな かった。

\section{N. 考察}

\section{1. 溶融金属亡繊維との接触角の評価}

水平な板上の液滴は理論的には観察方向によらず，一定 の值をとるが，纎維上の液滴は繊維軸方向と瀻維軸に対し て垂直な方向とでは接触角の值は異なることが考穴られ る. 


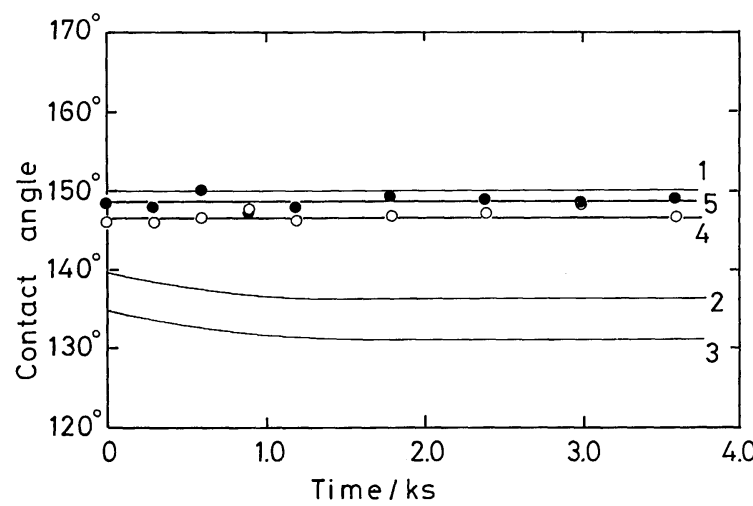

Fig. 8 Time dependence of the contact angle of liquid pure $\mathrm{Sn}$ on $\mathrm{SiC}$.

1: Hot-pressed $\mathrm{SiC}+1$ mass $\% \mathrm{~B}_{4} \mathrm{C}$ at $1373 \mathrm{~K}^{(1)}$.

2: Single crystal of $\alpha$-SiC at $1297 \mathrm{~K}^{(2)}$.

3: Reaction-bonded $\mathrm{SiC} 1373 \mathrm{~K}^{(1)}$.

4: Present work, $\mathrm{SiC}$ fibre (A) at $1373 \mathrm{~K}$.

5: Present work, SiC fibre (B) at $1373 \mathrm{~K}$.

Fig. 9 に繊維軸方向と繊維軸に対して垂直な方向におけ る液滴の接触の状況を模式的に示す。本研究において得ら れた接触角の值はいずれも繊維軸に対して平行な状態の接 触角の值 (Fig. 9(a))である. 繊維軸に対して垂直な状態の 接触角の值 (Fig. 9(b)) は凝固後の滴の形状から以下のよ らに算出した。

凝固滴の室温における接触角， $\theta^{\prime}$ ，は式 $(3)$ で表わすこ とができる。

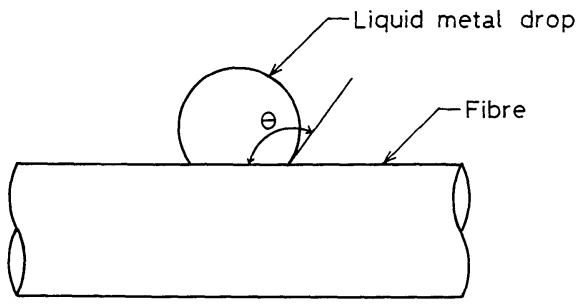

(a) Measured contact angle.

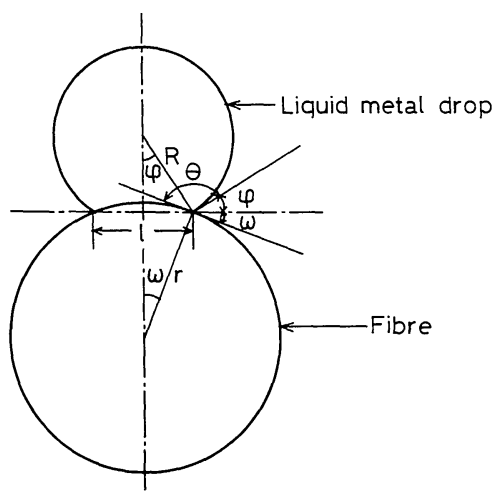

(b) Contact angle of liquid metal drop on cross section of fibre.

Fig. 9 Profile of metal drop on SiC fibre.

$$
\theta^{\prime}=180-(\phi+\omega)=180-\left\{\sin ^{-1}\left(\frac{l}{2 R}\right)+\sin ^{-1}\left(\frac{l}{2 r}\right)\right\}
$$

ここで, $R$ : 凝固滴の室温における半径 $(\mu \mathrm{m}), r$ : 繊維の 半径 $(\mu \mathrm{m}), l$ : 滴と繊維の接触部分に抢ける弦の長さ $(\mu \mathrm{m})$

式 (3) から, $\theta^{\prime}$ を求める際に必要な $R, r, l$ の值は凝固後 の金属滴を繊維軸に対して垂直に切断後, SEM 観察の結 果から求めた。その観察結果の一例を Fig. 10 亿, 測定結 果の一例を Table 1 に示す。

本研究では，溶融純 $(\mathrm{Cu}, \mathrm{Sn}, \mathrm{Ag}) / \mathrm{SiC}$ 繊維系のいずれ についても，凝固後に金属と繊維との界面観察のための断 面の研摩時に金属試料が $\mathrm{SiC}$ 繊維から剥離し, SEM によ る観察を行うことができなかった。したがって，繊維軸に 垂直な方向の接触角の評価のためには $\mathrm{Cu}-\mathrm{Ni}$ 合金を用い た.

得られた $\theta^{\prime} か ら$ 測定温度における接触角， $\theta$ ，の評価は 以下の手順によった.

繊維の半径， $r$ ，と滴と緎維の接触部分における弦の長 さ, $l$, の熱膨張係数は等しいと仮定し， $\beta-\mathrm{SiC}$ 繊維の熱 膨張係数の值 ${ }^{(6)}$ ， $3.8 \times 10^{-6} \mathrm{~K}^{-1}$ ，を採用した。 また金属 滴の熱膨張係数に関してはここでは $\mathrm{Cu}$ の固体状態, 液体 状態に打壮る従来の報告值 ${ }^{(7)}(8), 20 \times 10^{-6} \mathrm{~K}^{-1}, 34 \times 10^{-6}$ $\mathrm{K}^{-1}$ をそれぞれ採用した。さらに融解にともなら体積膨張

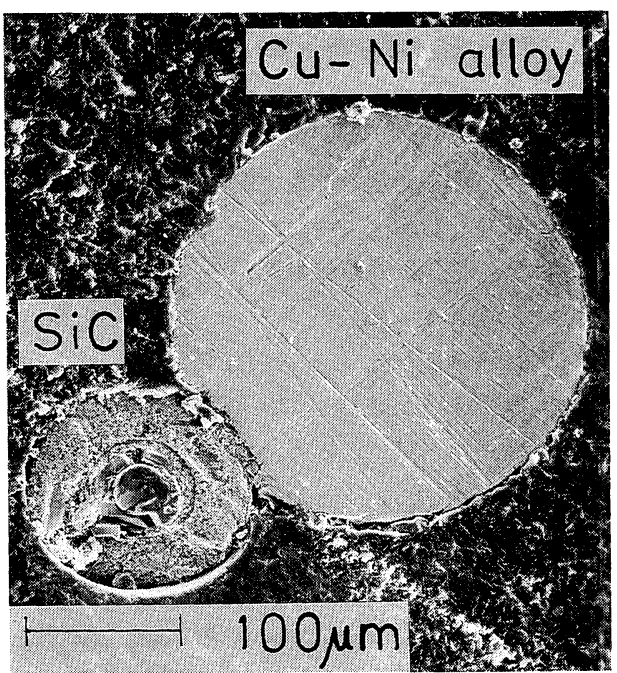

Fig. 10 SEM observation at cross section $\mathrm{Cu}-$ 2 mass $\% \mathrm{Ni}$ alloy/SiC fibre (A).

Table 1 Contact angle of liquid $\mathrm{Cu}-\mathrm{Ni}$ alloy on the cross section of fibre.

\begin{tabular}{c|c|c|c|c|c|c|c|c}
\hline \hline & \multicolumn{3}{|c|}{$\begin{array}{c}\text { Cu-2 mass\%Ni/SiC } \\
\text { fibre(A) }\end{array}$} & \multicolumn{4}{c}{$\begin{array}{c}\text { Cu-5 mass\%Ni/SiC } \\
\text { fibre(A) }\end{array}$} \\
\hline $\begin{array}{c}\text { Temp. } \\
/ \mathrm{K}\end{array}$ & $\begin{array}{c}\text { Fibre } \\
r / \mu \mathrm{m}\end{array}$ & $\begin{array}{c}\text { Drop } \\
\mathrm{R} / \mu \mathrm{m}\end{array}$ & $\begin{array}{l}\text { Chord } \\
l / \mu \mathrm{m}\end{array}$ & $\begin{array}{c}\theta \\
/ \text { degree }\end{array}$ & $\begin{array}{c}\text { Fibre } \\
r / \mu \mathrm{m}\end{array}$ & $\begin{array}{c}\text { Drop } \\
\mathrm{R} / \mu \mathrm{m}\end{array}$ & $\begin{array}{l}\text { Chord } \\
l / \mu \mathrm{m}\end{array}$ & $\begin{array}{c}\theta \\
/ \text { degree }\end{array}$ \\
\hline R.T. & 78.8 & 145.1 & 79.6 & 133.7 & 78.8 & 32.3 & 44.8 & 119.6 \\
\hline $1473 \mathrm{~K}$ & 79.2 & 151.9 & 79.9 & 134.5 & 79.2 & 33.8 & 45.0 & 121.8 \\
\hline
\end{tabular}


についてはfcc 金属では一般に3.9\%〜 6.3\%とされてお り (9),ここでは6.3\%を採用した。

これらの值を用い，室温に敊ける凝固滴と $\mathrm{SiC}$ と接 触角から測定温度に却ける接触角の䛧を計算すると，

Table 1 の值はそれぞれ134.5，121.8となる.

繊維軸の断面に和ける接触角の計算値は䋐維軸に対して 平行な滴の形状から求机た接鰠角の值，133.7\%, $120.5^{\circ}$ とは，測定誤差を考慮するとよい一致を示している といえる。

このよらに瀻維軸と平行な接触角と繊維軸に対して垂直 な方向の接触角との間に優位な相違がみられなかったの は，金属滴が十分に小さく，重力の影響がなかったため䋐 維の曲率の影響が現れなかったことによると考えられる。

\section{2. 溶融純金属と $\mathrm{SiC}$ 繊維との接触角}

Fig. 5 から明らかなよらに, $\mathrm{Ar}+5 \% \mathrm{H}_{2}$ 䨌团気での溶融 純 $\mathrm{Cu}$ と $\mathrm{SiC}$ 絨維との接触角は著者らの一部が以前に行 った $\mathrm{Ar}$ 雲囲気でのホットプレス $\mathrm{SiC}$ の易合(1) と同様に時 間依存性はみられなかった。以前の報告で反応焼結 $\mathrm{SiC}$ の場合には時間の経過にともなって接触角の減少が観察さ

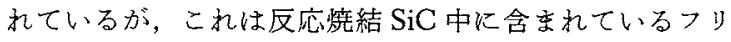
一 Si が溶 $\mathrm{Cu}$ 中へ溶解することによることが明らかにさ れている。この采に批いては, 測定後の試料が研摩の時点 で繊維から外れ飛散したために Cu中の $\mathrm{Si}$ の定量分析は 行えなかったが，接触角の時間依存性がみられなかったこ とから Cu中への Si の溶解はほとんどなかったと予想さ れる。

Fig. 6 の減王下の測定では，1393K の温度に柇いては 接触角の時間变化は観察されないが，1443Kでは時間の 経過にとあなって接触角の減少がタられた。しかしこの接 触角の減少は濡れ性の改善, すなわら溶融純 $\mathrm{Cu} と \mathrm{SiC}$

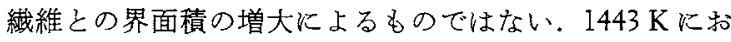
いては测定開始後 $3.6 \mathrm{ks}$ 後には $\mathrm{Cu}$ の蒸発により初期の Cu 滴の体積の約 $30 \%$ にな゙減少したことが観察された。 また，擮維軸と平行な界面の長さは測定開始直後の約 $70 \% に$ に減少した。このことから界面積は接触直後の ほば50\%にまで成少していると考学られる。したがって， $1443 \mathrm{~K}$ に和いて観察された接触角の減少は溶融純 $\mathrm{Cu}$ $\mathrm{SiC}$ 繊維との界面に和㲿る反㐫古るいは相互作用の増大に よるのではなく，滴の蒸発によって後退接触角が観察され たことによると思われる。

Fig. 7 に示したよらに，溶融 $\mathrm{Ag}$ と $\mathrm{SiC}$ 繊維との接触角 はいずれの温度においても高い值を示し，濡れなかった。 しかし1323 K, $1373 \mathrm{~K}$ とでは接触角の時間依存性は異なっ た傾向を示した。

$1323 \mathrm{~K}$ においては接触角の時間依存性はみられなかっ た，湘定温度が異なるために，単純には此較できないが著 者らの一部による溶融 $\mathrm{Ag}$ とホットプレス $\mathrm{SiC}$ の測定(1)(3) および表面を炭素処理した反応焼結 $\mathrm{SiC} の$ 測定 ${ }^{(3)} に$ 和い
ても接触角の時間依存性はみられなかった。

一方，1373 Kに和いては測定開始時における接触角は $1323 \mathrm{~K}$ の值よりも約 $10^{\circ}$ 低く，時間の経過にともなってい ずれの繊維の場合も接触角の減少がみられた。

また，繊維 Aについては約 $1.5 \mathrm{ks}$ で，繊維 Bについて は0.9 ksで，いずれの場合も溶融 $\mathrm{Ag} の$ 表面の金属光沢は 失われ，固相の析出がみられたここの固相の組成は明らか にはできなかったが溶融 $\mathrm{Ag}$ 中に溶解した Si，C，あるい

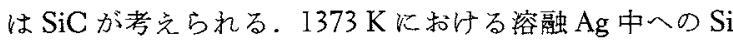
の溶解度は27 at\%であると報告されている(10). 凝固後の 試料中の Si 量はEDXによる定量分析の結果，2.76 at \% であった，したがって，Siが固相として析出することは 考光られない。李大溶融 $\mathrm{Ag}$ 中への C の溶解度は1933 K で0.01 at\%とされている(9)が，Ag-Si-C系の状態図に関す る報告は著者らの知るかぎり現在までなされていない，

このような濡れ性の測定の際に溶融金属表通における固 相の析出は著者らが以前に溶融純 $\mathrm{Cu} に よ る$ 単結晶 $\mathrm{SiC}$ の濡れ性を検討した際においても観察されている(4).

溶融純 $\mathrm{Cu}$ と単結晶 $\mathrm{SiC}$ とが接触後, 短時間の間に界 面において観察された固相は減圧下の測定においてのみ観 察され，大気圧下に打いては観察されなかったこと，凝固 後のCu 中の $\mathrm{Si}$ の分析結果および界面の EPMAによる観 察から固相の出現は $\mathrm{SiC}$ 可能性が高いことを述べてい るが，CuとAg の蒸気圧がいずれも高く，Siを溶解する か，Cをはとえど溶解しないといら物理的性質の類似性 から，本研究に拈いてみられた固相す $\mathrm{SiC}$ であことが 予想されるがこの点に関してはより詳細な検討が必要であ る.

Fig. 8 から明らかなよ5に，溶融 $\mathrm{Sn}$ と $\mathrm{SiC}$ 瀻維との接 触角は同一温度で行った著者らの以前のホットプレス $\mathrm{SiC}$ の結果(1)と類似の傾向を示した，以前の反応結 $\mathrm{SiC}$ の結果とは接触角がかなり異なるが，これは反応焼結 $\mathrm{SiC}$ 中に含まれるフリーSi の溶融 $\mathrm{Sn}$ 中への溶解による ものと考光られる.

\section{V. 結言}

$\mathrm{Cu}, \mathrm{Ag}, \mathrm{Sn}$ の粉末を用い，静滴法によって2種類の $\mathrm{SiC}$ 繊維の需れ性を減圧下および $\mathrm{Ar}+\mathrm{H}_{2}$ 雲囲気で测定を 行ない,以下の結果を得た。

（1）需孔ない系においては $\mathrm{SiC} の$ 基盤による測定結果 から $\mathrm{SiC}$ 繊維の濡れ性を評価することが可能であると考 克られる。

（2）溶融金属滴が小さく，滴の形状に対して重力の影 響が無視できる場合には， $\mathrm{SiC}$ の繊維軸方向の接触角は瀻 維軸の断面方向の接触角とほぼ等しい值が得られる.

（3）溶融純 $\mathrm{Cu}, \mathrm{Ag}, \mathrm{Sn}$ と $\mathrm{SiC}$ 緎維との接触角はすべ ての測定で $90^{\circ}$ 以上の高い值を示し, 繊維の種類, 雾囲気 の相違による接触角に差異はみられなかった。 
本研究に赫いて，Auger 分析を行っていただいた金属材 料技術研究所 塩田一路博士に心から感謝いたします。

本研究の一部は軽金属奨学会の援助によって遂行されま した.ここに記して感謝いたします。

\section{文献}

（1）野城 清, 荻野和巳: 日本金属学会誌, 52(1988), 786.

（2）野城 清，池田幸治，嶋田脩造，荻野和巳：日本金 属学会誌, 28(1988), 663 .
(3) K. Nogi and K. Ogino: Trans. JIM, 29 (1988), 742.

(4) K. Nogi and K. Ogino: Trans. JIM, 29(1988), 805.

(5) R. W. Bartlett and J. K. Hall: Ceram. Bull., 44 (1965), 444.

(6) C. H. Anderson and R. Warren: COMPOSITES, 15(1984), 16.

(7) E. Widawski and F. Sauerwald: Z. anorg. u. allgem. chem., $192(1930), 145$.

(8) J. A. Caill and A. D. Kirschenbaum: J. Phys. Chem., 66(1962), 1080.

(9) S. A. Cho: Z. Metallk., 71 (1980), 47.

(10) M. Hansen: Costitution of Binary Alloys, 2nd ed., McGraw-Hill, New York, (1958), p. 51. 